\title{
Medicare expenditures for elderly patients undergoing surgical clipping or endovascular intervention for subarachnoid hemorrhage
}

\author{
Kimon Bekelis, MD, ${ }^{1,2}$ Daniel J. Gottlieb, MS, ${ }^{2}$ Yin Su, MS, ${ }^{2}$ Giuseppe Lanzino, MD, ${ }^{3}$ \\ Michael T. Lawton, MD, ${ }^{4}$ and Todd A. MacKenzie, PhD $2,5,6$ \\ ${ }^{1}$ Section of Neurosurgery; ${ }^{6}$ Department of Medicine, Dartmouth-Hitchcock Medical Center; ${ }^{2}$ The Dartmouth Institute for Health \\ Policy and Clinical Practice, Lebanon; ${ }^{5}$ Department of Biomedical Data Science, Geisel School of Medicine at Dartmouth, \\ Hanover, New Hampshire; ${ }^{3}$ Department of Neurosurgery, Mayo Clinic, Rochester, Minnesota; and ${ }^{4}$ Department of Neurosurgery, \\ University of California San Francisco Medical Center, San Francisco, California
}

OBJECTIVE The impact of treatment method-surgical clipping or endovascular coiling —on the cost of care for patients with aneurysmal subarachnoid hemorrhage $(\mathrm{SAH})$ is debated. Here, the authors investigated the association between treatment method and long-term Medicare expenditures in elderly patients with aneurysmal SAH.

METHODS The authors performed a cohort study of $100 \%$ of the Medicare fee-for-service claims data for elderly patients who had undergone treatment for ruptured cerebral aneurysms in the period from 2007 to 2012 . To control for measured confounding, the authors used propensity score-adjusted multivariable regression analysis with mixed effects to account for clustering at the hospital referral region (HRR) level. An instrumental variable (regional rates of coiling) analysis was used to control for unmeasured confounding by creating pseudo-randomization on the treatment method.

RESULTS During the study period, 3210 patients underwent treatment for ruptured cerebral aneurysms and met the inclusion criteria. Of these patients, 1206 (37.6\%) had surgical clipping and 2004 (62.4\%) had endovascular coiling. The median total Medicare expenditures in the 1st year after admission for SAH were $\$ 113,000$ (IQR $\$ 77,500-\$ 182,000)$ for surgical clipping and $\$ 103,000$ (IQR \$72,900-\$159,000) for endovascular coiling. When the authors adjusted for unmeasured confounders by using an instrumental variable analysis, clipping was associated with increased 1-year Medicare expenditures by $\$ 19,577$ (95\% Cl \$4492-\$34,663).

CONCLUSIONS In a cohort of Medicare patients with aneurysmal SAH, after controlling for unmeasured confounding, surgical clipping was associated with increased 1-year expenditures in comparison with endovascular coiling.

https://thejns.org/doi/abs/10.3171/2016.2.JNS152994

KEY WORDS cerebral aneurysms; subarachnoid hemorrhage; cost; clipping; coiling; instrumental variable; Medicare; vascular disorders

$\mathrm{T}$ HE treatment of subarachnoid hemorrhage (SAH) has changed dramatically ${ }^{3,16}$ since the publication of the International Subarachnoid Aneurysm Trial (ISAT) ${ }^{30}$ which highlighted the value of endovascular interventions for ruptured cerebral aneurysms., ${ }^{3,33}$ Despite initial criticism about the study's design and limited focus, further national investigations $\mathbf{s}^{4,5,8,9,13,17,22}$ and a North American trial ${ }^{29}$ confirmed its findings. These results have fueled an explosive growth of coiling in the SAH population. ${ }^{3}$ However, as endovascular options are increasingly becoming technologically sophisticated, they are associated with rising device costs. Concerns have been raised that this cost outweighs the cost of clipping, which involves less expensive implants. With health care economic sustainability a national priority ${ }^{20}$ demonstrating the financial viability of new treatment options is crucial. ${ }^{1,2,11,12,14,15,18,24,26,28,32}$

Several studies have analyzed the economic aspects of cerebral aneurysm interventions. ${ }^{19,22,25,27,36,38}$ However, the generalizability of their findings is limited given the lack of adjustment for unmeasured confounding. In addition, most investigators have focused only on hospitalization cost, which does not take into account the cost of possible future reintervention in endovascularly treated patients or the cost of long-term care in patients experiencing complications. ${ }^{7,10,19,22,23,25,38}$ The investigators of the ISAT reported

ABBREVIATIONS COPD = chronic obstructive pulmonary disease; HRR = hospital referral region; ISAT = International Subarachnoid Aneurysm Trial; IV = instrumental variable; NIS = Nationwide Inpatient Sample; SAH = subarachnoid hemorrhage; ZIP = Zone Improvement Program.

SUBMITTED December 21, 2015. ACCEPTED February 2, 2016.

INCLUDE WHEN CITING Published online May 20, 2016; DOI: 10.3171/2016.2.JNS152994. 
no difference in the long-term cost of clipping or coiling among patients participating in the study. ${ }^{36}$ However, this study was conducted in Europe more than 10 years ago and does not reflect the current financial realities of North America. In addition, extrapolating the results of highly selective, well-controlled randomized trials to the real world should be done with caution, especially as regards underrepresented populations. There has been no prior investigation into the comparative long-term cost of clipping and coiling in elderly patients while appropriately controlling for unmeasured confounders.

Thus, we performed a national cohort study of Medicare patients with aneurysmal $\mathrm{SAH}$, investigating the association between treatment method and Medicare expenditures for elderly patients in the 1st year post-SAH. To control for unmeasured confounding (mainly the different patient characteristics and the nonrandom selection of treatments), we used an instrumental variable (IV) approach, simulating pseudo-randomization on the treatment method.

\section{Methods}

\section{Data and Cohort Creation}

The Dartmouth Committee for the Protection of Human Subjects approved this study. The data were anonymized and de-identified prior to use; therefore, no informed consent was required. We used $100 \%$ of the Medicare Denominator File and corresponding Medicare inpatient and outpatient claims, Parts A and B, for 2007-2012 (Medicare Provider Analysis and Review [MEDPAR], Carrier and Outpatient Claims) to select patients with aneurysmal $\mathrm{SAH}$. For cohort inclusion, patients were required 1) to be continuously enrolled in fee-for-service Medicare Parts A and B for 12 months before the index diagnosis, 2) to be an age of 65 years or older at the time of the index diagnosis, and 3) to have no secondary insurance at any point during the study.

\section{Intervention}

We used ICD-9-CM codes to identify patients presenting with aneurysmal SAH (ICD-9-CM code 430) who underwent clipping (code 39.51) or coiling (code 39.52 [should also have a code 88.41 and no 39.51 during the same hospitalization], 39.72, 39.75, 39.76, 39.79) between 2007 and 2012.

\section{Outcome Variables}

The primary outcome was the 1-year total Medicare expenditures, starting on the admission day for the SAH. Secondary outcome was 7-day total Medicare expenditures, starting on the admission day for the SAH. These calculations included the exact amount paid for all billing claims generated. Expenditures were inflation adjusted to reflect 2012 US dollar values.

\section{Covariates}

Age categories $(65-69,70-74,75-79,80-84,85-99$ years) were created, as well as 5 ethnicity and race categories (Asian, black, Hispanic, Native American, and other, with white being the excluded variable). The enrollee's
Zone Improvement Plan (ZIP) code was used to match to 2010 census data on income and poverty. We included the ZIP-level poverty rate separately from the income variable to reflect the differing distribution of income within the ZIP code.

Comorbidities diagnosed (in more than 2 outpatient and/or 1 inpatient encounter) at any time in the 12-month look back (before the intervention), for which outcomes were adjusted (Supplemental Table 1), included hypertension, myocardial infarction, cardiac arrhythmia, congestive heart failure, hyperlipidemia, coagulopathy, hypertension, ischemic stroke, peripheral vascular disease, chronic obstructive pulmonary disease (COPD), other pulmonary disease, diabetes, obesity, alcohol abuse, malignancy, and dementia.

Each facility was identified with one of the 306 hospital referral regions (HRRs) in the US as used by The Dartmouth Atlas of Health Care. An HRR is a region served by a hospital or group of hospitals that offers cardiovascular and neurosurgical procedures so that each HRR includes at least 1 tertiary care hospital. All ZIP codes in the US were assigned to an HRR on the basis of the migration patterns of hospital use among the elderly population. The coiling rate in each HRR was calculated by dividing the number of coiling procedures in an HRR by the number of total interventions for ruptured cerebral aneurysms in the same location and time period.

\section{Statistical Analysis}

To compare total Medicare expenditures between coiling and clipping therapies, we initially used multiple linear regression, adjusting for all the covariates listed above to address known confounders. As an alternative way to control for measured confounding, we employed a linear regression with adjustment (stratification) by quantiles (we chose the number of quantiles as 20) of the propensity score. To derive the propensity of clipping versus coiling, we developed a prediction model using logistic regression based on all the covariates described above. All these models included a random intercept for HRR. In a sensitivity analysis, we repeated all approaches after logarithmic transformation of expenditures. The results were similar and are therefore not reported further.

Patients have different neurological statuses and baseline characteristics and have already been selected for clipping or coiling, which can affect the outcomes as well as the cost of these interventions. To overcome this confounding (the nonrandom selection of patients for either treatment) due to covariates not captured by Medicare, we employed an IV analysis, ${ }^{21}$ which uses the differences in practice patterns across regions to simulate the structure of a randomized trial in an observational setting. This advanced observational technique has been used by clinical researchers to answer comparative effectiveness questions for different interventions. The goal is to simulate randomization, especially when the baseline functional characteristics of the patients are unknown (similar to our application). ${ }^{31,35,37}$

The use of coiling varies widely across HRRs. Patients tend to seek care for emergencies such as SAH close to their residence. Someone who lives in an HRR in which coiling is primarily offered is more likely to receive this 
treatment. The IV approach depends on the assumptions that HRR coiling rates affect outcomes only by promoting the use of coiling in that HRR (exclusion restriction criterion) and that there are no variables that affect both the regional coiling rate and costs (no instrument-outcome confounders) besides those adjusted for, as in the linear regression models above. Hospital referral region coiling rates were not correlated with the average predicted cost within an HRR, based on covariates controlled for in the regression models presented $(r=0.01, p>0.10)$, suggesting a case mix balance between HRRs. A practical rule ${ }^{34}$ for employing an instrument is that the F-statistic (or chisquare for a binary exposure) for the association between the instrument and the treatment exceeds 10 . In our study, this value was 125 when using HRR coiling rates as an instrument for coiling.

We subsequently calculated the causal estimate of the differences in total Medicare expenditures between clipping and coiling by using a linear regression model with an IV analysis in a 2-stage least squares approach, as described in the literature. . $, 31,35,37$ The HRR coiling rate was used as an instrument for coiling, and we also adjusted for all other covariates listed above. In sensitivity analysis we excluded patients with less than 1 year of follow-up from our models. The direction of the observed associations did not change; therefore, these results are not reported further.

Given that 2004 patients underwent coiling and 1206 underwent clipping, we had an $80 \%$ power to detect a difference in cost as small as $4.0 \%$ at an $\alpha$-level of 0.05 , assuming a log-normal distribution with a mean of $\$ 107,000$ and an IQR of $\$ 75,000-\$ 168,000$. All probability values were the result of 2-sided tests. The SAS version 9.4 (SAS Institute Inc.) and the 64-bit version of R.2.12.2 (R Foundation for Statistical Computing) were used for statistical analysis.

\section{Results \\ Patient Characteristics}

From 2007 to 2012, 3210 Medicare patients underwent treatment for ruptured cerebral aneurysms and met the inclusion criteria for this study. Of these patients, 1206 (37.6\%) had surgical clipping and 2004 (62.4\%) had endovascular coiling. The respective distribution of exposure variables between the 2 methods of treatment can be found in Table 1. Figure 1 demonstrates the distribution of coiling rates per HRR.

\section{7-Day Total Medicare Expenditures}

The median total Medicare expenditures in the first 7 days after admission for the SAH were $\$ 38,400$ (IQR $\$ 29,200$ to $\$ 50,100$ ) for surgical clipping and $\$ 38,400$ (IQR $\$ 29,600$ to $\$ 52,200$ ) for endovascular coiling. As demonstrated in Table 2, there was no association between treatment method and 7-day expenditures (adjusted difference $-\$ 887,95 \%$ CI $-\$ 2483$ to $\$ 709$ ) in the unadjusted analysis. This finding persisted when adjusting for measured confounders with a linear regression model (adjusted difference $-\$ 971,95 \%$ CI $-\$ 2574$ to $\$ 632$ ) and a propensity-adjusted regression model (adjusted difference $-\$ 958$, $95 \%$ CI $-\$ 2560$ to $\$ 643)$. Similarly, when we adjusted for
TABLE 1. Summary of patient characteristics*

\begin{tabular}{|c|c|c|c|}
\hline Characteristic & Clipping & Coiling & $\begin{array}{c}\text { Z } \\
\text { Value }\end{array}$ \\
\hline No. of patients & 1206 & 2004 & \\
\hline Mean age in yrs (SD) & $73.5(6.2)$ & $75.3(6.8)$ & 7.4 \\
\hline Male sex & $275(22.8 \%)$ & $533(26.6 \%)$ & -2.4 \\
\hline African American race & $135(11.2 \%)$ & $208(10.4 \%)$ & 0.7 \\
\hline $\begin{array}{l}\text { Income in } 2012 \text { US\$ } \\
\text { (SD) } \dagger\end{array}$ & $\$ 44,800(\$ 17,900)$ & $\$ 45,700(\$ 17,700)$ & -1.4 \\
\hline Poverty† & $137(11.4 \%)$ & $210(10.5 \%)$ & 3.1 \\
\hline \multicolumn{4}{|l|}{ Comorbidity $\ddagger$} \\
\hline Hypertension & $421(34.9 \%)$ & $859(42.9 \%)$ & -4.5 \\
\hline Hyperlipidemia & $166(13.7 \%)$ & $294(14.7 \%)$ & -0.7 \\
\hline COPD & $20(1.7 \%)$ & $33(1.6 \%)$ & 0.02 \\
\hline Myocardial infarction & $97(8.0 \%)$ & $223(11.1 \%)$ & -2.8 \\
\hline Cardiac arrhythmia & $51(4.2 \%)$ & $135(6.7 \%)$ & -3.0 \\
\hline Coagulopathy & $\S$ & $17(0.8 \%)$ & -1.2 \\
\hline Renal insufficiency & $42(3.5 \%)$ & $67(3.3 \%)$ & 0.2 \\
\hline $\begin{array}{l}\text { Congestive heart } \\
\text { failure }\end{array}$ & $27(2.2 \%)$ & $82(4.1 \%)$ & -2.8 \\
\hline Pulmonary disease $\Uparrow$ & $25(2.1 \%)$ & $47(2.3 \%)$ & -0.5 \\
\hline Obesity & $\S$ & $\S$ & 0.5 \\
\hline Alcohol abuse & $\S$ & $\S$ & -0.8 \\
\hline Dementia & $\S$ & $31(1.5 \%)$ & -2.0 \\
\hline Ischemic stroke & $39(3.2 \%)$ & $89(4.4 \%)$ & -1.7 \\
\hline Diabetes & $123(10.2 \%)$ & $241(12.0 \%)$ & -1.6 \\
\hline $\begin{array}{l}\text { Peripheral vascular } \\
\text { disease }\end{array}$ & $51(4.2 \%)$ & $142(7.1 \%)$ & -3.3 \\
\hline Malignancy & $58(4.8 \%)$ & $132(6.6 \%)$ & -2.1 \\
\hline \multicolumn{4}{|c|}{$\begin{array}{l}\text { SD = standard deviation. } \\
\text { * Values represent crude numbers. } \\
\dagger \text { The enrollee's ZIP code was used to match to } 2010 \text { census data on income } \\
\text { and poverty. } \\
\text { ‡ Based on } 12 \text {-month look back before the date of the procedure. } \\
\S \text { Output suppressed to comply with the reporting rules of Medicare, which do } \\
\text { not allow printing of output involving less than } 11 \text { patients. } \\
\text { I Non-COPD. }\end{array}$} \\
\hline
\end{tabular}

unmeasured confounders by using an IV analysis, treatment choice was not associated with 7-day Medicare expenditures (adjusted difference $-\$ 438,95 \%$ CI $-\$ 4368$ to \$3491).

\section{1-Year Total Medicare Expenditures}

The median total Medicare expenditures in the 1st year after admission for the SAH were $\$ 113,000$ (IQR $\$ 77,500-\$ 182,000)$ for surgical clipping and $\$ 103,000$ (IQR \$72,900-\$159,000) for endovascular coiling. As demonstrated in Table 2, surgical clipping was associated with increased 1-year expenditures by $\$ 11,379$ (95\% CI \$5480-\$17,278) in the unadjusted analysis. Adjusting for measured confounders with multiple linear regression (adjusted difference $\$ 9484,95 \%$ CI $\$ 3363-\$ 15,605$ ) or a propensity score-adjusted regression (adjusted difference \$9937, 95\% CI \$3789-\$16,086) confirmed this association. When we controlled for unmeasured confounders by using an IV analysis, clipping was associated with in- 


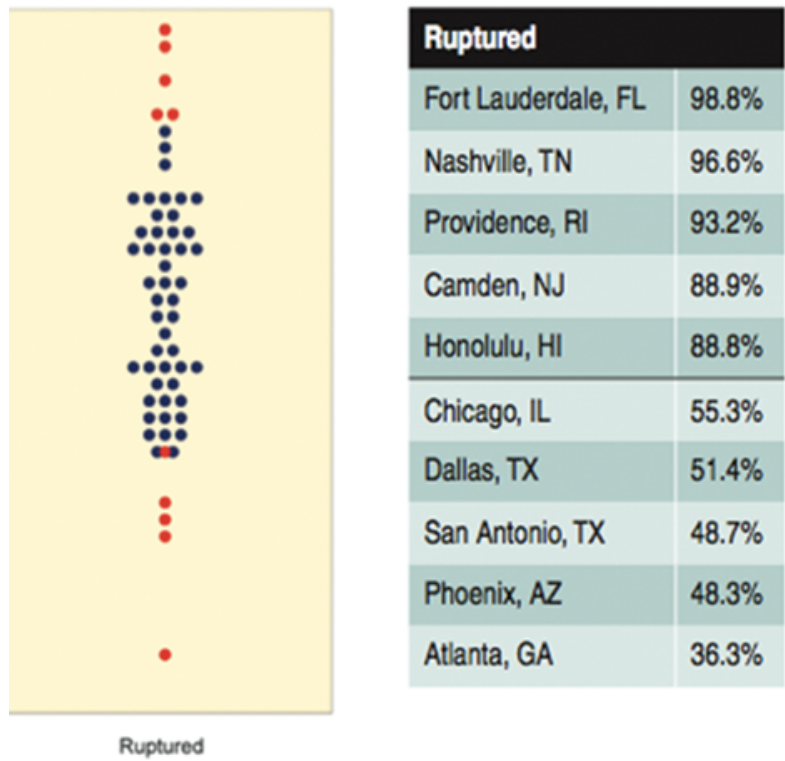

FIG. 1. Percent of Medicare beneficiaries treated for ruptured cerebral aneurysms using coiling (2007-2012). Each dot represents 1 HRR; the higher the dot, the higher the percentage. Each blue dot represents the percentage of Medicare beneficiaries treated for ruptured cerebral aneurysms with coiling in 1 of 306 HRRs in the US. Red dots indicate the regions with the 5 lowest and 5 highest rates, whose names are listed to the right. Reproduced from Bekelis K. Variation in the Care of Surgical Conditions: A Dartmouth Atlas of Health Care Series. Lebanon, NH, 2014. Published with permission. Figure is available in color online only.

creased 1-year Medicare expenditures by $\$ 19,577$ (95\% CI \$4492-\$34,663).

\section{Discussion}

Among Medicare patients undergoing treatment for ruptured cerebral aneurysms, we identified an association between surgical clipping and increased Medicare expenditures at 1 year after the day of admission for SAH. There was no difference in expenditures in the first 7 days after admission. In recent years, the pendulum has swung dramatically in favor of endovascular interventions for aneurysmal SAH. However, the comparative cost of long-term care in patients undergoing these interventions remains an issue of debate.

Prior long-term economic analyses of these groups have limited generalization. Wolstenholme et al., ${ }^{36}$ in a post hoc analysis of the ISAT, were unable to demonstrate a difference in the 1-year cost of care in patients undergoing clipping or coiling. However, the results of this trial were limited to Europe, with its different financial environments in each country, and reflect prices and technologies that are now more than 10 years old. In the last decade endovascular interventions have seen a dramatic increase in effectiveness but also in cost, enhancing this debate. More recently, other investigator $\mathrm{s}^{27}$ used a commercial database to assess the cost-effectiveness of clipping and coiling in the setting of SAH. However, the cost calculations in that study were based on assumptions and extrapolation of data from other investigations and did not represent the exact costs incurred during the procedures. Therefore, it is questionable whether these findings give a true picture of the economic impact of the 2 interventions. In addition, participation in the database was voluntary, and it is likely that hospitals incentivized to achieve higher quality standards would be overrepresented. This self-selection introduces significant unmeasured confounding, which the authors did not account for.

Other studies focusing on the hospitalization cost of cerebral aneurysm treatment have demonstrated conflicting results. Although single-center investigations have shown a lower hospitalization cost for coiling, ${ }^{19,22,25,38}$ a retrospective analysis of the Nationwide Inpatient Sample $(\mathrm{NIS})^{23}$ showed that clipping was associated with higher hospitalization charges for both ruptured and unruptured aneurysms. Utilizing the same national database, Bekelis et al. ${ }^{7,10}$ developed a predictive model of hospitalization cost for these patients. However, cost calculations based on the NIS are crude and mostly derived from charges and therefore do not reflect true cost. In addition, the available data refer to the acute hospitalization only and do not allow the study of the long-term financial impact of these procedures. Lastly, the lack of adjustment for clustering and rigorous control for unmeasured confounders significantly limits the interpretation of the results of these prior analyses.

Our study addresses many of these methodological limitations. First, we created a cohort of almost all elderly patients in the US, giving a true picture of national practice in this age group. Second, we used advanced observational techniques to control for confounding. The prior selection of patients for either procedure (based on their different neurological statuses and characteristics) will undoubtedly bias the outcomes and thus the comparative cost of the 2 procedures. We used an IV analysis to account for such bias. This approach simulates the effect of randomization on treatment by controlling for unknown confounders (that is, neurological status at presentation, aneurysm size, and

TABLE 2. Correlation between clipping and outcome measures

\begin{tabular}{|c|c|c|c|c|}
\hline \multirow[b]{2}{*}{ Model } & \multicolumn{2}{|l|}{ 1-Yr Expenditures* } & \multicolumn{2}{|c|}{ 7-Day Expenditures* } \\
\hline & Adjusted Difference $(95 \% \mathrm{Cl})$ & $p$ Value & Adjusted Difference $(95 \% \mathrm{Cl})$ & $\mathrm{p}$ Value \\
\hline Crude & $\$ 11,379(\$ 5,480$ to $\$ 17,278)$ & $<0.001$ & $-\$ 887(-\$ 2,483$ to $\$ 709)$ & 0.276 \\
\hline Multivariable regression $†$ & $\$ 9,484(\$ 3,363$ to $\$ 15,605)$ & $<0.001$ & $-\$ 971(-\$ 2,574$ to $\$ 632)$ & 0.235 \\
\hline Propensity-adjusted regression† & $\$ 9,937(\$ 3,789$ to $\$ 16,086)$ & $<0.001$ & $-\$ 958(-\$ 2,560$ to $\$ 643)$ & 0.241 \\
\hline Instrumental variable analysisł & $\$ 19,577(\$ 4,492$ to $\$ 34,663)$ & $<0.001$ & $-\$ 438(-\$ 4,368$ to $\$ 3,491)$ & 0.827 \\
\hline
\end{tabular}


location). In contrast to some prior studies, which lacked long-term cost analysis, we modeled our primary outcome as 1-year expenditures to account for possible future reintervention in some patients or the cost of long-term care in patients experiencing complications. Third, our cost calculations were based on exact Medicare expenditures for each patient over time. This accurately reflected the true financial impact of those procedures, contrary to prior investigations focusing on charges or estimates.

Our analysis provides insight into the economic aspects of available treatments for aneurysmal SAH. It addresses a common misconception that endovascular interventions are more costly. The care of individual patients should be directed according to their specific characteristics and not by the cost of the respective procedures. However, our data provide an additional argument in favor of the economic sustainability of endovascular options, which can be used in the debate with policy makers, payers, and administrators as new treatments that can benefit neurosurgical patients are introduced. It is likely that the increased expenditures associated with clipping are secondary to the higher percentage of patients discharged to rehabilitation facilities $, 4,5$ resulting in increased spending. However, we are lacking the granularity to identify the exact components contributing to the total yearly cost of either procedure. More detailed analyses can be performed with the creation of large, long-term registries, and such efforts are underway (http://www.neuropoint.org/NPA\%20N2QOD. aspx). These registries can integrate quality of life outcome measures (such as the modified Rankin Scale) or patient satisfaction metrics to reach meaningful conclusions about cost-effectiveness.

Our study has several limitations common to administrative databases. First, the study is observational. We used multiple techniques (multivariable regression, HRR random effects, propensity score adjustment, IV analysis) to account for known and unknown confounders. To the extent that the HRR coiling rate is a good instrument, the possibility of residual confounding is small. Our first stage F-statistic was consistent with a strong instrument, ${ }^{34}$ and it is unlikely that the regional rate of coiling will be associated with costs in any other way than the choice of treatment. Second, coding inaccuracies can affect our estimates. However, coding for procedures is rarely inaccurate given that it is a revenue generator and is under scrutiny by payers.

Third, claims data do not provide metrics on the postoperative neurological status of patients (that is, modified Rankin Scale score), chronic pain, or quality of life; therefore, we cannot analyze the difference between clipping and coiling in regard to these measures. Fourth, findings among this older American population may not be generalizable to younger or otherwise dissimilar populations. Although our results accurately reflect the cost of cerebral aneurysm treatment for Medicare, we cannot generalize these results for other payers or private insurers. Fifth, we have no information on aneurysm size, location, and details of treatment, which can affect expenditures. However, the use of an IV analysis is expected to simulate a randomized trial and control for such unknown confounders. Sixth, causal inference is hard to establish based on observational data, even when using an IV analysis. ${ }^{21}$

\section{Conclusions}

The cost difference between the 2 treatment options of surgical clipping and endovascular coiling for ruptured cerebral aneurysms remains an issue of debate. We investigated the association between treatment method and Medicare expenditures in elderly patients with aneurysmal SAH. In a cohort of Medicare patients, after controlling for unmeasured confounding, we demonstrated that surgical clipping of ruptured cerebral aneurysms was associated with increased 1-year expenditures.

\section{Acknowledgments}

This study was partially supported by Grant No. UL1TR001086 from the National Center for Advancing Translational Sciences (NCATS) of the National Institutes of Health for the Dartmouth Clinical and Translational Science Institute.

\section{References}

1. Barker FG II, Amin-Hanjani S, Butler WE, Hoh BL, Rabinov JD, Pryor JC, et al: Age-dependent differences in shortterm outcome after surgical or endovascular treatment of unruptured intracranial aneurysms in the United States, 1996-2000. Neurosurgery 54:18-30, 2004

2. Barker FG II, Amin-Hanjani S, Butler WE, Ogilvy CS, Carter BS: In-hospital mortality and morbidity after surgical treatment of unruptured intracranial aneurysms in the United States, 1996-2000: the effect of hospital and surgeon volume. Neurosurgery 52:995-1009, 2003

3. Bekelis K: Variation in the care of surgical conditions: cerebral aneurysms, in Goodney RP, Dzebisashvili N, Goodman DC, et al (eds): Variations in the Care of Surgical Conditions: A Dartmouth Atlas of Health Care Series. Lebanon, NH: Dartmouth Institute for Health Policy and Clinical Practice, 2014

4. Bekelis K, Gottlieb D, Su Y, O’Malley AJ, Labropoulos N, Goodney P, et al: Surgical clipping versus endovascular coiling for elderly patients presenting with subarachnoid hemorrhage. J Neurointerv Surg [epub ahead of print], 2015

5. Bekelis K, Missios S, Coy S, Rahmani R, Singer RJ, MacKenzie TA: Surgical clipping versus endovascular intervention for the treatment of subarachnoid hemorrhage patients in New York state. PLoS One 10:e0137946, 2015

6. Bekelis K, Missios S, Coy S, Singer RJ, MacKenzie TA: New York state: comparison of treatment outcomes for unruptured cerebral aneurysms using an instrumental variable analysis. J Am Heart Assoc 4:e002190, 2015

7. Bekelis K, Missios S, Labropoulos N: Cerebral aneurysm coiling: a predictive model of hospitalization cost. J Neurointerv Surg 7:543-548, 2015

8. Bekelis K, Missios S, Mackenzie TA, Desai A, Fischer A, Labropoulos N, et al: Predicting inpatient complications from cerebral aneurysm clipping: the Nationwide Inpatient Sample 2005-2009. J Neurosurg 120:591-598, 2014

9. Bekelis K, Missios S, Mackenzie TA, Fischer A, Labropoulos $\mathrm{N}$, Eskey C: A predictive model of outcomes during cerebral aneurysm coiling. J Neurointerv Surg 6:342-348, 2014

10. Bekelis K, Missios S, MacKenzie TA, Labropoulos N, Roberts DW: A predictive model of hospitalization cost after cerebral aneurysm clipping. J Neurointerv Surg 8:316-322, 2016

11. Blackburn SL, Abdelazim AM, Cutler AB, Brookins KT, Fargen KM, Hoh BL, et al: Endovascular and surgical treatment of unruptured MCA aneurysms: meta-analysis and review of the literature. Stroke Res Treat 2014:348147, 2014

12. Brilstra EH, Rinkel GJ, van der Graaf Y, Sluzewski M, Groen RJ, Lo RT, et al: Quality of life after treatment of 
unruptured intracranial aneurysms by neurosurgical clipping or by embolisation with coils. A prospective, observational study. Cerebrovasc Dis 17:44-52, 2004

13. Brinjikji W, Lanzino G, Rabinstein AA, Kallmes DF, Cloft HJ: Age-related trends in the treatment and outcomes of ruptured cerebral aneurysms: a study of the Nationwide Inpatient Sample 2001-2009. AJNR Am J Neuroradiol 34:1022-1027, 2013

14. Brinjikji W, Rabinstein AA, Lanzino G, Kallmes DF, Cloft HJ: Effect of age on outcomes of treatment of unruptured cerebral aneurysms: a study of the National Inpatient Sample 2001-2008. Stroke 42:1320-1324, 2011

15. Brinjikji W, Rabinstein AA, Lanzino G, Kallmes DF, Cloft HJ: Patient outcomes are better for unruptured cerebral aneurysms treated at centers that preferentially treat with endovascular coiling: a study of the National Inpatient Sample 2001-2007. AJNR Am J Neuroradiol 32:1065-1070, 2011

16. Brisman JL, Song JK, Newell DW: Cerebral aneurysms. N Engl J Med 355:928-939, 2006

17. Chang TR, Kowalski RG, Carhuapoma JR, Tamargo RJ, Naval NS: Impact of case volume on aneurysmal subarachnoid hemorrhage outcomes. J Crit Care 30:469-472, 2015

18. Darsaut TE, Estrade L, Jamali S, Bojanowski MW, Chagnon $\mathrm{M}$, Raymond J: Uncertainty and agreement in the management of unruptured intracranial aneurysms. J Neurosurg 120:618-623, 2014

19. Duan Y, Blackham K, Nelson J, Selman W, Bambakidis N: Analysis of short-term total hospital costs and current primary cost drivers of coiling versus clipping for unruptured intracranial aneurysms. J Neurointerv Surg 7:614-618, 2015

20. Fisher ES, McClellan MB, Safran DG: Building the path to accountable care. N Engl J Med 365:2445-2447, 2011

21. Garabedian LF, Chu P, Toh S, Zaslavsky AM, Soumerai SB: Potential bias of instrumental variable analyses for observational comparative effectiveness research. Ann Intern Med 161:131-138, 2014

22. Hoh BL, Chi YY, Dermott MA, Lipori PJ, Lewis SB: The effect of coiling versus clipping of ruptured and unruptured cerebral aneurysms on length of stay, hospital cost, hospital reimbursement, and surgeon reimbursement at the University of Florida. Neurosurgery 64:614-621, 2009

23. Hoh BL, Chi YY, Lawson MF, Mocco J, Barker FG II: Length of stay and total hospital charges of clipping versus coiling for ruptured and unruptured adult cerebral aneurysms in the Nationwide Inpatient Sample database 2002 to 2006. Stroke 41:337-342, 2010

24. Hoh BL, Rabinov JD, Pryor JC, Carter BS, Barker FG II: Inhospital morbidity and mortality after endovascular treatment of unruptured intracranial aneurysms in the United States, 1996-2000: effect of hospital and physician volume. AJNR Am J Neuroradiol 24:1409-1420, 2003

25. Kim M, Park J, Lee J: Comparative cost analysis for surgical and endovascular treatment of unruptured intracranial aneurysms in South Korea. J Korean Neurosurg Soc 57:455459,2015

26. Kotowski M, Naggara O, Darsaut TE, Nolet S, Gevry G, Kouznetsov E, et al: Safety and occlusion rates of surgical treatment of unruptured intracranial aneurysms: a systematic review and meta-analysis of the literature from 1990 to 2011. J Neurol Neurosurg Psychiatry 84:42-48, 2013

27. Maud A, Lakshminarayan K, Suri MF, Vazquez G, Lanzino G, Qureshi AI: Cost-effectiveness analysis of endovascular versus neurosurgical treatment for ruptured intracranial aneurysms in the United States. J Neurosurg 110:880-886, 2009

28. McDonald JS, McDonald RJ, Fan J, Kallmes DF, Lanzino G, Cloft HJ: Comparative effectiveness of unruptured cerebral aneurysm therapies: propensity score analysis of clipping versus coiling. Stroke 44:988-994, 2013

29. McDougall CG, Spetzler RF, Zabramski JM, Partovi S, Hills NK, Nakaji P, et al: The Barrow Ruptured Aneurysm Trial. J Neurosurg 116:135-144, 2012

30. Molyneux A, Kerr R, Stratton I, Sandercock P, Clarke M, Shrimpton J, et al: International Subarachnoid Aneurysm Trial (ISAT) of neurosurgical clipping versus endovascular coiling in 2143 patients with ruptured intracranial aneurysms: a randomised trial. Lancet 360:1267-1274, 2002

31. Neuman MD, Rosenbaum PR, Ludwig JM, Zubizarreta JR, Silber JH: Anesthesia technique, mortality, and length of stay after hip fracture surgery. JAMA 311:2508-2517, 2014

32. Park JH, Kim YI, Lim YC: Clinical outcomes of treatment for intracranial aneurysm in elderly patients. J Cerebrovasc Endovasc Neurosurg 16:193-199, 2014

33. Qureshi AI, Vazquez G, Tariq N, Suri MF, Lakshminarayan K, Lanzino G: Impact of International Subarachnoid Aneurysm Trial results on treatment of ruptured intracranial aneurysms in the United States. Clinical article. J Neurosurg 114:834-841, 2011

34. Staiger D, Stock JH: Instrumental variables regression with weak instruments. Econometrica 65:557-586, 1997

35. Tan HJ, Norton EC, Ye Z, Hafez KS, Gore JL, Miller DC: Long-term survival following partial vs radical nephrectomy among older patients with early-stage kidney cancer. JAMA 307:1629-1635, 2012

36. Wolstenholme J, Rivero-Arias O, Gray A, Molyneux AJ, Kerr RS, Yarnold JA, et al: Treatment pathways, resource use, and costs of endovascular coiling versus surgical clipping after aSAH. Stroke 39:111-119, 2008

37. Xian Y, Holloway RG, Chan PS, Noyes K, Shah MN, Ting $\mathrm{HH}$, et al: Association between stroke center hospitalization for acute ischemic stroke and mortality. JAMA 305:373380,2011

38. Zubair Tahir M, Enam SA, Pervez Ali R, Bhatti A, ul Haq T: Cost-effectiveness of clipping vs coiling of intracranial aneurysms after subarachnoid hemorrhage in a developing country-a prospective study. Surg Neurol 72:355-361, 2009

\section{Disclosures}

Dr. Lanzino is a consultant for Covidien/Medtronic. The funders had no role in the design or execution of the study.

\section{Author Contributions}

Conception and design: Bekelis. Acquisition of data: Bekelis, Gottlieb, Su, MacKenzie. Analysis and interpretation of data: all authors. Drafting the article: Bekelis. Critically revising the article: Gottlieb, Lanzino, Lawton, MacKenzie. Reviewed submitted version of manuscript: Bekelis. Approved the final version of the manuscript on behalf of all authors: Bekelis. Statistical analysis: Bekelis, Gottlieb, Su, MacKenzie. Administrative/technical/material support: Bekelis. Study supervision: Bekelis.

\section{Supplemental Information}

Online-Only Content

Supplemental material is available with the online version of the article.

Supplemental Table 1. http://thejns.org/doi/suppl/10.3171/2016. 2.JNS152994.

\section{Correspondence}

Kimon Bekelis, Section of Neurosurgery, Dartmouth-Hitchcock Medical Center, One Medical Center Dr., Lebanon, NH 03755. email: kbekelis@gmail.com. 